\title{
A quién miramos sin saber por qué: Juliana los mira de Evelio Rosero
}

\author{
Who do we look at without knowing why: Juliana los mira \\ by Evelio Rosero
}

\section{Angela M. GonzÁlez Echeverry*}

Resumen:

El presente artículo propone la lectura de Juliana los mira, novela publicada en 1987 por el escritor colombiano Evelio Rosero, como bisagra entre dos discursos en tensión: la igualdad como derecho fundamental en la Constitución de Colombia y las prácticas culturales contemporáneas, para entender hacia dónde apunta la retórica de género en Colombia hoy día. Para este análisis se toma en cuenta el erotismo poético de los sentidos en la construcción de la identidad de género de la protagonista de la novela. Juliana los mira crea un espacio narrativo idóneo para la fragmentación, la duda y la exploración de las identidades de género, cuya consecuencia es la posible reformulación del poder de lo corpóreo y del erotismo como fuentes fundamentales tanto de la narración como de la identidad. El artículo se acerca a la realidad sociopolítica del país por medio de dos eventos fundamentales en los cuales se aspira a definir y limitar el alcance del derecho a la igualdad. Se enuncian las interferencias sociales y culturales que permiten volver sobre la retórica de género, para comprender la dirección de este derecho fundamental en el contexto actual.

\footnotetext{
* Gulf University for Sciences and Technology, Kuwait.
} 
Palabras clave:

igualdad, Colombia, identidad de género, Evelio Rosero, erotismo.

Abstract:

This article proposes reading Juliana los mira —a 1987 novel by Colombian author Evelio Rosero-as a pivot between two contentional discourse practices regarding equality: that of the Colombian Constitution which recognizes it as a fundamental right, and that of equality within contemporary cultural practices. With the intention of understanding where does Gender Rhetoric lead to in Colombia; and to reveal those possible fissures that permeate the right to equality enshrined in the constitutional norm. This analysis takes into account the poetic eroticism of the senses, in the construction of the mains character's gender identity. Juliana los mira creates a narrative space ideal for fragmenting, doubting and exploring gender identities, which consequence is the reformulation of the notion that the power of the corporeal and eroticism as fundamental sources of both narration and identity. The article approaches the socio-political reality of the country through two fundamental events hoping to define and delimit the scope of the right to equality. The social and cultural interferences are enunciated, through Gender Rhetoric, in order to understand the general direction of this fundamental right within its current context.

Keywords:

Equality, Colombia, Gender Identity, Evelio Rosero, Eroticism.

El hombre normal considera enfermizas las paradojas de lo divino y del erotismo.

Georges Bataille

\section{Contexto y paradoja}

Propongo la lectura de Juliana los mira, una novela publicada en 1987 y que pertenece con Mateo solo (1984) y El incendiado (1988) a una trilogía del escritor colombiano Evelio Rosero, como bisagra 
entre dos discursos en tensión: la legalidad y las prácticas culturales, para entender hacia dónde apunta la retórica del género en Colombia hoy día. En esta búsqueda se advertirán enunciados de género alternativos cuyo sentido va fracturando la retórica binaria que imposibilita el pleno ejercicio de la igualdad. Cabe señalar que, al hablar de género, el referente primordial de análisis en este estudio es la norma constitucional colombiana ${ }^{1}$. Hay dos razones principales para volver sobre la norma: la primera tiene relación con la idea de que la Constitución es la plataforma originaria de la legalidad, es decir, el instrumento que define las garantías y los límites en caso de cualquier discrepancia socio-jurídica. En segundo lugar, es claro que la norma constitucional pauta el camino del deber ser del que se desprenden las instituciones políticas y sociales de un estado democrático de derecho. Teniendo en cuenta este criterio, la Constitución de 1991 es el texto enunciador de la naturaleza y el alcance de la igualdad de género como un derecho de primer orden en la trayectoria civil y política del quehacer subjetivo de los ciudadanos nacionales.

Pese al poder soberano de la Constitución, hay muchos otros elementos que van influenciando tanto el entendimiento del género como el acceso a las garantías derivadas de los derechos fundamentales. Aquí específicamente me refiero a asuntos puntuales en el espacio político y social que han marcado la tendencia que aqueja la aplicación del derecho a la igualdad y las garantías de los sujetos de derechos. Asimismo, la idea trazada de usar la novela Juliana los mira como bisagra de aquellos discursos en tensión servirá para

1 “Artículo 13. Todas las personas nacen libres e iguales ante la ley, recibirán la misma protección y trato de las autoridades y gozarán de los mismos derechos, libertades y oportunidades sin ninguna discriminación por razones de sexo, raza, origen nacional o familiar, lengua, religión, opinión política o filosófica. El Estado promoverá las condiciones para que la igualdad sea real y efectiva y adoptará medidas en favor de grupos discriminados o marginados. El Estado protegerá especialmente a aquellas personas que por su condición económica, física o mental, se encuentren en circunstancia de debilidad manifiesta y sancionará los abusos o maltratos que contra ellas se cometan". 
enunciar otras formas identitarias de género que han sido marginadas a la luz de valores que contradicen la igualdad como una realidad jurídica efectiva. En este tejido social contradictorio, el estudio de Juliana los mira puede sin duda incomodar, porque la novela es la historia de dos niñas y el descubrimiento de sus identidades de género y su sexualidad. Los sucesos se describen sin tapujos, desde un erotismo libre de cualquier aprobación moral o religiosa que va más allá de la fórmula binaria.

El concepto de erotismo está relacionado con la obra de Georges Bataille $e^{2}$ en particular con la idea de discontinuidad como esencia de lo humano. El abismo irreductible entre un ser y otro se traduce en un sentimiento de ausencia de continuidad que resulta difícil de soportar y que produce un angustioso deseo por combatir lo perecedero. Este sentimiento de interrupción de su propia naturaleza que obsesiona al sujeto es el vínculo que el individuo/ ser establece con lo humano/seres. Bataille señala que sufrir el aislamiento y la individualidad discontinua solo puede vencerse con la muerte, porque al morir el ser/individuo regresa a la continuidad que no es otra cosa que la total ausencia de particularidad. El erotismo, por tanto, es una búsqueda humana incesante y su máxima expresión es el abandono total del sentido de particularidad y el fin de la discontinuidad. El erotismo apunta hacia la transgresión de aquellas prohibiciones que particularizan las acciones humanas, pero, como toda transgresión, no puede existir sin el miedo a lo prohibido/pecado. Bataille señala que:

Lo que hace difícil hablar de la prohibición no es solamente la variabilidad de sus objetos, sino el carácter ilógico que posee. Nunca, a propósito de un mismo objeto, se hace imposible una proposición opuesta. No existe prohibición que no pueda ser transgredida. Y, a menudo, la transgresión es algo admitido, o incluso prescrito. (46)

${ }^{2}$ Este escritor de origen francés (1897-1962) señala que el erotismo es punto esencial del entendimiento humano "de modo que está situado en la cima del espíritu humano" (201). 
El goce del erotismo requiere de quien lo experimenta un vínculo con la angustia de un ser consciente, "se trata entonces de responder a la voluntad inscrita en nosotros de exceder los límites. Queremos excederlos, y el horror experimentado significa el exceso al cual debemos llegar" (108). Esta conciencia difiere de la sexualidad animal y hace posible la movilización de la vida interior del sujeto erótico. El objeto del deseo responde precisamente a la interioridad del sujeto. De aquí que el autor compara la poesía con el erotismo. Ambos espacios subjetivos culminan en el mismo punto: la eternidad/la continuidad. En suma, el erotismo para Bataille lleva a la consciencia y la conciencia a la prohibición "la cima del ser sólo se revela por entero en el movimiento de transgresión” (203). Esta transgresión es el fundamentado del desarrollo de la conciencia humana. Una conciencia que deja al desnudo un sujeto incompleto y perecedero.

En concordancia con lo previamente mencionado, la novela $J u$ liana los mira recurre al erotismo para revelar las identidades de las personajes mientras fragmenta ese sentimiento de discontinuidad del que habla Bataille. En este camino, la exploración no implica una narración sosegada ni para la personaje ni para los lectores. Las respuestas no están dadas y más bien lo que se procura es insertar pliegues a las designaciones tradicionales de género. A través de la novela se descubre que la identidad puede tomar diversas formas y que las expectativas derivadas de la familia y el entorno social en general son insuficientes para definir la subjetividad y la sexualidad como elementos identitarios determinantes.

Ahora bien, curiosamente la novela salió treinta años atrás en España y aunque fue traducida al alemán y puesta en circulación en los Países Bajos, solo hasta el 2015 el autor pudo publicar esta obra tal cual él quería. La edición de 2015 de Tusquets incluye una nota de Rosero explicando cómo la novela nunca llegó a Colombia y tampoco tuvo difusión, señalando que "la pusieron a dormir en bodega durante los años que contemplaba el contrato” (161). Además de no haber circulado en Colombia, el mismo autor sugiere que la novela envejeció al igual que él ha envejecido y que solo hasta ahora se atreve a presentarla, porque sin duda está "aligerada de adjetivos ... y reiteraciones” (162). En efecto, Rosero tenía razón al no ha- 
berse atrevido a presentar su novela treinta años atrás. La exploración de las identidades que desarrolla la historia y la construcción del género desde la subjetividad femenina son aspectos que pueden resultar escandalosos e incómodos aun hoy día. La reedición de la novela, a pesar de haber aligerado el lenguaje, no cambió aquella búsqueda identitaria y erótica de la protagonista que para los años ochenta no planteaba alternativas al binarismo. Por el contrario, en la actualidad, la novela permite que el discurso de género dialogue con la realidad del país, gracias a aquellos lectores formados en una realidad mucho más inclusiva creada por la Constitución de 1991 que reconoce formas alternativas e igualitarias de subjetividad.

También es importante señalar que esta novela ha sido una de las menos estudiadas por la crítica literaria en comparación con otras obras de Rosero ampliamente analizadas. Para destacar está Anatomía de una seducción (2013) de Alejandro Varderi. Este compendio estudia varios escritores en busca de "perfilar lo femenino" y señala que, en el caso de Evelio Rosero, la novela en cuestión subvierte "los géneros ... a fin de abarcar el proceso de feminización o "gynesis», y establecer nuevas relaciones entre la techné masculina y la physis femenina" (147). Seguidamente, Varderi apunta que Juliana, la protagonista, "se aleja del estereotipo de la joven sumisa" utilizando un lenguaje provocativo "sin establecer juicios de valor", con el fin de hacer del lector un "voyeur privilegiado" (156). De hecho, concluye que Rosero no oculta la bisexualidad de la chica logrando abrir lo femenino y escribir con su cuerpo. La agudeza de Juliana los mira, según Varderi, reside en que se agrietan los espacios de la identidad como fundamento de un sujeto femenino creado a través de la escritura de un autor masculino heterosexual. El artículo indica que la apertura de Rosero en cuanto a las categorías de género es un acto celebratorio de la sexualidad y de la naturaleza femenina, que le devuelve al sujeto el placer y el cuerpo que han permanecido sellados.

Vale la pena también mencionar el estudio de Vivian Carolina Rojas Caicedo. Su tesina de maestría dedica una buena parte a esta novela estableciendo la importancia del ojo transgresor y señalando que el erotismo, las drogas y la ensoñación son elementos funda- 
mentales de la novelística de Rosero. La tesis de Rojas Caicedo concluye que la novela desacraliza las relaciones sociales y familiares excediendo todas las fronteras y creando una "memoria erótica de una nueva generación que busca más que nada rebasar sus propias fronteras" porque la mirada de Juliana "es un hacer, que trastorna su mundo" (44). En este sentido, el establecimiento de la memoria erótica a la que se refiere la tesina amplía el entendimiento de la subjetividad femenina y va más allá de la nota predominante sobre la caracterización de la novela como literatura erótica.

Algunas reseñas mencionan que las acciones de los personajes y la moral simulada de estos exhiben las situaciones anómalas y de corrupción en las que están envueltos los personajes. A este línea pertenece la reseña de Steven M. DuPouy, que aparece en Latin American Writers on Gay and Lesbian Themes: A Bio-Critical Sourcebook. DuPouy señala que la relación lésbica de Juliana se aprovecha para subrayar la "totally depraved society"3 (386) y anota que los juegos sexuales de las chicas representan el lado de la sociedad que debe permanecer oculto y que, por tanto, Rosero utiliza para vehiculizar su disgusto y discrepancia sobre ciertos eventos en Colombia.

Por último, mencionaré un artículo de Paula Andrea Marín Colorado que se incluye en el libro De la abyección a la revuelta: la nueva novela colombiana de Evelio Rosero, Tomás Gonzálezy Antonio Ungar. Dicho artículo, que estudia de forma general la novelística de Rosero, establece que su obra es crucial a la hora de comprender los hechos violentos de la sociedad colombiana. El argumento conclusivo de Marín Colorado es que Rosero posibilita un distanciamiento entre el lector y el mundo ficcional para así promover una verdadera crítica sobre la realidad nacional. En concreto, el artículo que estudia Juliana los mira concluye que la corrupción institucional, la violencia sexual y los vicios ilegales son circunstancias tímidamente intuidas por la personaje principal por ser apenas una niña. Apunta que "ni siquiera hay cuestionamiento sobre estos actos; la confusión de Juliana la lleva a asumir una actitud ambigua ante lo que experimenta"

\footnotetext{
3 "sociedada totalmente depravada".
} 
(11). La conclusión del artículo refuerza el sentimiento de vaguedad de la protagonista con relación a su entorno y a su propia identidad, lo que contradice la idea de que Rosero promueve una crítica de la realidad nacional.

Contrario a lo que presenta este último estudio, el entendimiento que la chica tiene del mundo que habita, a pesar de su corta edad, dista de ser una simple asimilación carente de cuestionamiento. Por consiguiente, propongo a continuación que Juliana, la personaje principal de la novela de Rosero, intuitivamente observa y mira para derribar lo que no comprende. De hecho, es a través de este personaje que se estimula un viraje hacia el erotismo — esa búsqueda humana de la que habla Bataille_ lo que suscita una identidad de género que auxilia el presente del sujeto llevando a cabo un ejercicio poético desgarrador y delirante. Este movimiento sensorial resulta en un enfoque transversal que permea el discurso de género hoy día. De tal manera, como bien lo ha expuesto la crítica en diversas formas, la mirada transgresora de la narrativa de Rosero, especialmente en el contexto de Colombia, hace posible complejizar las definiciones simplistas y binarias de género. Así, esto conecta la novela con una problemática que se materializa en dos eventos que caracterizan a aquellos sectores sociales y políticos que insisten en imponer un discurso único de género binario con las correspondientes prácticas moralizantes, discurso que, a pesar de su popularidad, está en oposición a la garantía constitucional de igualdad creada a partir de la Constitución de 1991.

En asuntos de género, derechos sexuales y reproductivos, las posiciones de la sociedad colombiana se han radicalizado en los últimos tiempos. Estas grandes divisiones sociales se materializan en dos casos precisos que se analizarán a continuación. El primer caso tiene que ver con la polémica que se desató en Colombia en agosto de 2016 por la implementación de una cartilla de educación sexual en los colegios. Quienes se oponían a la implementación de esta cartilla acusaban que el Estado estaba inmiscuyéndose en sus creencias, principalmente en lo concerniente a los valores que eventualmente serían trasmitidos y promovidos a sus hijos con relación a la familia, el matrimonio y el género. 
El trasfondo de la implementación de las cartillas nos remite al suicidio de Sergio Urrego, un chico que sufrió discriminación en su colegio en razón de su homosexualidad. La muerte del joven y la acción de activistas de derechos de LGBTI (lesbianas, gays, bisexuales, transexuales e intersexuales) concluyó con un fallo de la Corte Constitucional ${ }^{4}$ que, además de establecer la existencia del hostigamiento o acoso escolar, conocido como "matoneo" (sufrido por Sergio Urrego por su identidad de género y su orientación sexual), exigió a las autoridades educativas, encabezadas por el Ministerio de Educación, la revisión de los manuales de convivencia en las escuelas y colegios nacionales, enfatizando la importancia de fomentar el ejercicio del libre desarrollo de la personalidad y el derecho a la educación. La gestión del ministerio fue entonces la publicación de una cartilla para las escuelas públicas, cuyo contenido incluía la promoción de la tolerancia y el respeto hacia los niños y niñas con orientación sexual diversa. En términos generales, la intención de esta cartilla, realizada con el apoyo de las Naciones Unidas y de la Organización Colombia Diversa ${ }^{5}$, era el cumplimiento de lo orde-

4 “ORDENAR al Ministerio de Educación Nacional que, en un plazo máximo de un (1) año contado a partir de la notificación de la presente sentencia, implemente acciones tendientes a la creación definitiva del Sistema Nacional de Convivencia Escolar de acuerdo a lo señalado por la Ley 1620 de 2013 y el Decreto 1965 de 2015. Particularmente, se ordena que en el plazo señalado, se adopten las siguientes medidas: i) una revisión extensiva e integral de todos los Manuales de Convivencia en el país para determinar que los mismos sean respetuosos de la orientación sexual y la identidad de género de los estudiantes y para que incorporen nuevas formas y alternativas para incentivar y fortalecer la convivencia escolar y el ejercicio de los derechos humanos, sexuales y reproductivos de los estudiantes, que permitan aprender del error, respetar la diversidad y dirimir los conflictos de manera pacífica, así como que contribuyan a dar posibles soluciones a situaciones y conductas internas que atenten contra el ejercicio de sus derechos; y ii) ordenar y verificar que en todos los establecimientos de educación preescolar, básica y media estén constituidos los comités escolares de convivencia." (“Sentencia T-478/15”).

5 "Fundada en 2004, Colombia Diversa es la organización de defensa de derechos humanos de las personas LGBT líder en Colombia. Su trabajo se centra en tres áreas principales: 1. Promover y defender los derechos humanos y legales de las 
nado por la Corte Constitucional. No obstante, pese a ser un fallo con fuerza vinculante para todos los ciudadanos, algunos, bajo el lema "gente de bien", salieron a las calles a protestar y marcharon en contra de las cartillas porque consideraban que estas imponían la ideología de género y estaban en contra de los valores tradicionales de la sociedad colombiana.

El concepto de ideología de género, que sin duda ha venido tomando fuerza en este debate, ha sido usado indistintamente tanto por líderes religiosos de diferentes denominaciones como por políticos y organizaciones civiles. Como lo señala Julieta Lemaitre, este término tiene sus orígenes en la doctrina de la Iglesia Católica, concretamente durante el papado de Juan Pablo II y Benedicto XVI. Lamaitre apunta que para quienes siguen esta orientación "la identidad sexual de las personas, así como los roles de género, son socialmente construidos y no eternos, esenciales y asignados por Dios". Lo que quiere decir que los opositores a la ideología de género se sienten amenazados con la idea de que el género es una construcción histórica, simbólica y social y no una predeterminación divina. Por el contrario, se subraya que la identidad sexual está plenamente establecida y que las pluralidades identitarias son una violación a la voluntad de dios y un pecado en contra de la moral, la familia y la sociedad. Significa entonces que los sujetos están interpelados por dos exclusivas categorías, que parecen enfrentarse y oponerse en el sentido de sus roles identitarios.

Esta realidad binaria se atribuye simplificando las posibilidades subjetivas de la propia enunciación. En efecto se crean fronteras reducidas por los modelos sociales que no solamente controlan los cuerpos, sino que establecen una identidad que a su vez crea un discurso social que legitima y refuerza los estereotipos. Asimismo, se crea una lógica contraria a la garantía constitucional del derecho a la igualdad. En consecuencia, coartar el espacio identitario del sujeto

personas LGBT en Colombia. 2. Trabajar para transformar positivamente las percepciones acerca de las personas LGBT en Colombia.3. La promoción de la organización y el impacto político de la comunidad LGBT en Colombia" ("Acerca de"). 
y de su cuerpo, y de otras formas no binarias de género es la antítesis de una agenda que garantiza la pluralidad de sus ciudadanos. En este sentido, la cartilla, fruto de la discordia, ordenada por la sentencia de la Corte, buscaba remediar una situación de inequidad, además de dictaminar el cumplimiento de la ley. Sin embargo, su implementación se percibió como una imposición por parte de la ministra de Educación Gina Parody, quien resultó seriamente atacada por su orientación sexual. Parody fue usada por la oposición para tachar la iniciativa y así evitar que la cartilla fuera implantada. Quienes protestaban reclamaron con el argumento de que la iniciativa del gobierno (creada como cumplimiento de una sentencia de la Corte) contravenía los valores cristianos ${ }^{6}$ y la familia.

En esta cruzada contra las cartillas, se deben mencionar dos personajes fundamentales, abanderados opositores del cumplimiento de la norma constitucional. El primero es Vivian Morales, senadora y organizadora de las marchas en contra de las cartillas. Su agenda política incluía, para ese momento, la promoción de un referendo en contra de la adopción por parte de parejas del mismo sexo. A la par está Alejandro Ordoñez, ex procurador general de Colombia (2008-2016), precandidato presidencial, enemigo del matrimonio entre personas del mismo sexo y visible contendiente del proceso de paz y de los acuerdos con la guerrilla. Ambos personajes fueron las cabezas visibles de la arremetida contra las cartillas. Vale mencionar que Ordoñez, a pesar de haber sido destituido de su cargo de procurador en el 2016 por una decisión del Consejo de Estado, influyó para que sus posturas ideológicas y políticas dividieran el país y luego marcaran las elecciones presidenciales en mayo de 2018. Los sectores sociales que se resisten a aceptar las cartillas no solo incumplen las normas vigentes de protección de los dere-

${ }^{6}$ Según Pew Research Center, Colombia es el sexto país con mayor cantidad de población católica en el mundo. El Vaticano, por medio de El Anuario Pontificio 2017, señaló que Colombia se ubica entre los diez países con mayor número de católicos en el mundo; concretamente ocupa el puesto número siete con 45,3 millones de bautizados. 
chos fundamentales contemplados en la Constitución colombiana vigente, sino que promueven la idea equivocada de que la igualdad es opcional y no un mandato y una garantía.

El segundo caso que materializa las divisiones sociales respecto a asuntos de género está relacionado con el contenido de los Acuerdos de Paz y la incorporación del concepto de género a lo largo del documento. El acuerdo define el concepto de la siguiente manera: "enfoque de género significa el reconocimiento de la igualdad de derechos entre hombres y mujeres y [de] las circunstancias especiales de cada uno (Acuerdo final 193). Esta declaración explícita, fue motivo de divergencia a la hora de votarse el plebiscito sobre el Acuerdo de Paz en octubre de 2016. Organizaciones religiosas y civiles se mostraron preocupadas y reacias al Acuerdo porque el enfoque de género, según su punto de vista, contravenía los derechos de las familias tradicionales. En este mismo sentido, también se popularizó la idea de que exigir la igualdad de derechos era al mismo tiempo promover y beneficiar a la comunidad LGBTI con la creación de políticas públicas que implicarían cambios profundos en instituciones como el matrimonio, la familia, la adopción y el estado civil. Cabe agregar que la Iglesia Católica, a través de sus delegados, se pronunció tanto en contra de la cartilla como del enfoque de género del Acuerdo, porque asumió que ambas instancias eran sobre todo inspiradoras de la homosexualidad y la ideología de género.

Nuevamente, la aplicación de las garantías constitucionales se vio supeditada a las opiniones de quienes se aseguran de impedir el acceso igualitario de los colombianos a sus derechos fundamentales, apelando a una moral superior al resto de los ciudadanos. Lo que los abanderados del NO hicieron a la hora de votar el Acuerdo de Paz, consistió en una campaña mediática en la que se exigía a los colombianos cristianos o católicos rechazar cualquier acuerdo o candidato que estableciera o apoyara la ideología de género. Los votantes perdieron de vista que dicho acuerdo buscaba la participación de las mujeres en el desarrollo de la paz y que se encaminaba a la eliminación de cualquier forma de discriminación. Dicho de otra manera, el texto de los acuerdos destacaba la importancia de las mujeres como agentes políticos y como piezas fundamentales en la 
consecución de la paz, combatiendo toda forma de discriminación y protegiendo a aquellos sujetos victimizados y discriminados por razón de género. Los votantes del NO y sus inspiradores desconocieron el valor de promover el ejercicio de la igualdad y reponer cualquier brecha originada en el conflicto entre los ciudadanos por razones de género. Al respecto, Génica Mazzoldi e Irina Cuesta señalan que:

Una de las características del proceso de negociación en La Habana fue la incorporación del enfoque de género como principio transversal y orientador en los seis puntos que componen el Acuerdo final ... Es más, el enfoque de género como medio o herramienta para que la equidad sea una realidad para los colombianos, hace parte de las políticas públicas desde tiempo atrás y es coherente con nuestro marco jurídico. De ahí la importancia que adquirió en el Acuerdo.

Dicho enfoque de género se fundamenta en el principio constitucional de la igualdad, es decir el reconocimiento de las mujeres y de la población LGBTI como "sujetos políticos y de derechos" (Mazzoldi). No obstante, lo que causa curiosidad y extrañeza, es que el hecho fue aprovechado erróneamente, como lo explica Mazzoldi y Cuesta, de forma confabulada por los partidarios del NO en detrimento de los derechos de los ciudadanos colombianos y en contra de la igualdad.

Lo que han generado estas dos situaciones en el país es una profunda polarización que se relaciona directamente con el derecho a la igualdad, específicamente en lo referente al género sexual y a la identidad. Esta división se vio reflejada en la campaña presidencial y en los discursos que acompañaron la elección del nuevo presiente de la República para el periodo 2018-2022. Las discrepancias se han venido materializando no solo en los discursos políticos y mediáticos sino también en el establecimiento de unos valores elementales que contradicen la diversidad de Colombia. Por una parte, está la Colombia heterogénea y tolerante a la diversidad de género, que sin duda reúne el sentir de un gran número de ciudadanos; y por 
otra está la Colombia que se autodenomina creyente y que abandera valores que se desprenden de los preceptos religiosos y de la moral cristiana, aun cuando contrarían las leyes vigentes. De estas tensiones se puede deducir que la igualdad, aunque es una garantía constitucional, está ligada a las fuerzas sociales y a la voluntad de una porción de la sociedad que se siente con el poder y el derecho de decidir los límites y los alcances de la ley, particularmente en lo atinente al género y a la identidad sexual. En suma, garantizar la igualdad de los ciudadanos, para los detractores de las cartillas y los opositores de la paz, es promover y estimular valores contarios a la moral, además de arrebatar a los padres y al estatus quo la potestad de educar conservando los privilegios de unos sectores y marginalizando todo aquello que no se ajuste a sus criterios.

\section{Incomodidad y erotismo femenino}

Como ya se estableció en páginas anteriores, el erotismo es punto esencial del entendimiento humano y requiere, de quienes lo experimentan, un vínculo de conciencia que necesariamente está cargado de la angustia de estar al tanto de la transgresión y de la condición de discontinuidad del ser. No obstante, Bataille añade que una forma de romper la discontinuidad es el goce del erotismo aun cuando se siente el pavor de la prohibición. En este sentido, la novela de Rosero responde al erotismo de la protagonista que la conduce a su propia consciencia y revela su transgresión. Juliana experimenta la continuidad de lo humano en aquellos momentos en los que la narración se aleja de toda forma impuesta de género. Dado lo anterior, retornar a la novela y encontrar el erotismo como fundamento de lo humano, y no como una vertiente definida por los roles de géneros designados, avala el derecho a la igualdad frente a aquellas interferencias morales opositoras de la diversidad que se aleja de la división binaria de género.

Del mismo modo, el espacio literario de la novela muestra que el erotismo fluye, se activa y se enuncia más allá de las normas impuestas. El género es un territorio de configuraciones múltiples y Juliana 
Los mira tiene el poder de reformular, representar y mirar la realidad desde lo insondable del sujeto femenino. En lugar de la experiencia moral, la novela narra los primeros encuentros de la protagonista sin evadir las múltiples ansiedades y las fracturas de aquellas identidades impuestas:

Cambiamos de zapatos, fue como si dijéramos las dos: nunca nunca nunca vamos a separarnos. Teníamos los pies iguales y reímos al cambiar de zapatos ... yo sentí que entraba en el calor de alguien distinto, yo sentí que al mismo tiempo alguien entraba en mi calor almacenando en mis zapatos que yo ya no tenía pero que sentía aun, como algo mío invisible invadido de alguien que no era yo, pero que por eso era yo, yo sentía que era un cambio de calor, un escalofrió terrible que no se si daba realmente risa o dolor o deseos tremendos de llorar de alegría, un dolor que nunca había sentido, sus zapatos ya eran míos pero no eran sólo míos. (46)

Ahora bien, el relato de Rosero empieza la víspera del cumpleaños número once de Juliana, cuando el padre le pregunta a su hija qué regalo quiere y la niña contesta que un barco de guerra. La respuesta toma por sorpresa al padre, quien responde: "Yo pensé que pedirías tres muñecas. ¡Una niña de diez años que pide un barco de guerra!" (Rosero 9). A pesar de su asombro, el padre promete que le comprará el barco. La novela termina la mañana del cumpleaños de la chica cuando se despierta y va en busca de su papá, quien aún duerme, para agradecerle el regalo: "lo primero que veo, contra la puerta cerrada, es otro sueño, un barco gigante, de guerra, y una cartulina que dice: feliz. cumpleaños" (151).

Este breve espacio temporal se conecta con zonas delirantes, donde Juliana, la protagonista, relata su amistad con Camila, la relación con su madre, el cariño que siente por su padre y el mundo en el que debe comportarse como una chica de bien: "tenía miedo porque son muchas las veces que mamá se queda mirándome y me dice Dios que vamos a hacer para quitarte esa cara de niño, Juliana, voy a tener que llevarte donde el doctor" (18). De este modo, la no- 
vela salpica al lector de manera sincrónica con los miedos pasados y futuros y con las vicisitudes que sufre la protagonista mientras emprende su búsqueda de identidad para subvertir el discurso de género binario a través de efectivos planos eróticos.

El proceso identitario de Juliana empieza sin duda con la curiosidad que le provoca Camila, quien se presenta en su casa con sus padres, invitados todos a una fiesta a la que también asisten políticos, periodistas y gente prestante de la sociedad:

Conocí a Camila y la envidié mucho porque tenía zapatos de tacón y se veía más alta que yo y parecía una señorita y yo solo era una niña. Pero cuando nos pusimos los vestidos de baño ambas nos veíamos iguales y no le sentí envidia y nadábamos, a pesar de que se había pintado las uñas de los pies y yo ni siquiera tenía pintadas las de mis manos. (18)

Juliana declara que Camila es capaz de hacer muchas cosas que sin duda ella no: "era capaz de todo; podía beber un vaso de vodka, podía volar. Por algo tenía pintadas las uñas" (25). La astucia de Camila para retar todo tipo de normas y ser capaz de hacer cualquier cosa, despierta en Juliana el deseo de disputar su propia identidad. La chica entiende que mirar a Camila la aproxima a sí misma, aunque aumenten sus miedos cuando se agudizan sus sentidos.

La narración de Juliana va hilvanando el mundo social y político en que vive, siempre desde una visión transversal que pasa por su amiga Camila: "las dos sabemos que esto es una culpa pero no lo es ... No somos las que somos y no somos porque no" (79). Esta chica rubia y de ojos "color verde brillantísimos" (17), comparte con la protagonista su condición de hija única, es de su misma edad y acaba de llegar a la ciudad después de vivir con sus padres en México. Además, sus madres son amigas. El universo creado por las chicas al entrar en contacto y conocerse desdibuja los parámetros de género determinados por las normas sociales y por los roles expresados en juegos de conveniencia social. A pesar de la prisión ejercida por su entorno, Juliana opta por el erotismo para explicarse su identidad de género. Los contornos en los que la protagonista decide ser 
fraccionan una serie de pautas que se esconden bajo la superficie de un mundo turbio y viciado que no reconoce ni acepta la pluralidad como prerrogativa en la configuración del género y la identidad.

La amistad de las chicas contextualiza el universo para Juliana, especialmente porque Camila actúa segura y competente percatándose de su propia existencia, de su cuerpo y de las fantasías de Juliana. La protagonista decide ser y sentir a través del erotismo que le despierta su amiga: "fue como si de improviso se separaran todas las sombras y dudas de toda mi vida y apareciera Camila entera y única en forma de luz" (29). Gracias a esta relación Juliana se piensa diferente, imagina que su nueva amiga la rescata y la hipnotiza: "yo sentía el perfume de Camila entre su pelo rubio mojado, que llegaba hasta la tierra como otra rama de sauce y me hacía cosquillas en la mejilla" (26). Este estado sorprende de igual forma al lector y a la personaje, sin que el miedo a romper las reglas impuestas por la madre detenga las acciones de aquella.

Evidentemente, desde el comienzo de la narración, el lector conoce el disgusto que siente la madre de la chica. Su universo normativo la lleva constantemente a criticar las acciones de Juliana y su reproche va más allá de la imposición hetera. La madre le grita: "iTe vas a callar, idiota, pareces un niño jugando!" (13). Este ejemplo de recriminación es constante y abrasivo, por eso la protagonista se asila en un mundo de animales, de enanos, gnomos, patos y cisnes de ojos fosforescentes. Sus sentidos se agitan y el erotismo se conecta con la mirada. Una mirada que no excluye a su madre y que, envuelta por la imaginación, espía los encuentros sexuales que esta tiene con el guardaespaldas de la familia.

La niña describe a su madre como una mujer lejana, una mancha casi traslúcida, un ser temeroso con aliento a alcohol que insistentemente se siente perturbada por su hija y sus juegos de niño. La madre oculta el engaño de una sexualidad fuera de su matrimonio y una vida miserable de amargura y aceptación. A la vez, es la encargada de censurar a Juliana insistiendo en que su comportamiento no es el de una niña. Así, la madre se erige como el estandarte y la veedora de las normas que constriñen a ambas. Esta posición de guarda moral se materializa en sentido más amplio en una socie- 
dad que defiende y patrocina la familia exclusivamente si se corresponde con lo establecido y que también es capaz de condenar la pluralidad de género, lo cual deja sin derechos al sujeto que no se conforma con la tradición binaria asignada por la norma moral en clara oposición a la ley.

Contraria a la madre, Juliana fragmenta desde adentro la familia tradicional y las normas de género iluminando lo incómodo y lo prohibido. La chica intuye sobrecogida las contradicciones de su madre y por tanto narra un erotismo lleno de evocaciones animalescas de los encuentros sexuales de su madre y Esteban, el guardaespaldas de la familia: "mamá debe ser un conejo huyendo y él un león. La voz de Esteban tiene que ser peluda. La voz de mamá una piel. No. La voz de mamá es en este instante un gato llorando” (66). Si bien la madre parece indefensa y acechada por el lobo grotesco de Esteban, de ningún modo deja de ser la guardiana de la identidad normativizada de Juliana. En medio de estas contradicciones, la narración renueva el valor del erotismo — esencia en palabras de Bataille- de ambos sujetos femeninos a través de sus encuentros eróticos, lo que estimula una exploración vital de la identidad de género, a pesar de la ansiedad que experimenta la chica.

Juliana reconoce las contradicciones entre las normas sociales al develar lo inagotable de la experiencia erótica del sujeto como rasgo distintivo de lo humano. En buena medida, la escritura de Rosero reformula el género, las obsesiones sociales y la realidad en sí misma como un campo abierto para las identidades. El cuerpo erótico funciona como un mecanismo textual que articula un modo de mirar la realidad, una forma porosa de percibirse como sujeto de deseo que desea y una enunciación que se olvida de los filtros normativos por medio de la imaginación y lo corpóreo. Es evidente entonces que Juliana trasforma su identidad, al parecer estática e impuesta por la madre, para intuir un relato propio en el que no es necesario pretender:

El agua era un espejo vivo: palpitaba azul como nosotras, igual que nuestras venas, un corazón. Había sido un juego largo y el aliento de Camila continuaba hirviendo en mi cuello. 
Durante ese instante quise que Camila no marchara nunca de mi casa y se quedara a vivir toda la vida, para hablar conmigo o para no hablar, para cerrar los ojos y abrirlos otra vez y acompañarme en tardes interminables como ésta — cuando estoy a solas y miro sola a mamá-, para defenderme del mundo y de mamá. Por un segundo sentí que ambas éramos una, y le dije: "Camila, no me dejes", y ella a mis espaldas se rió ... y volteé a mirarla y vi que pestañeaba suavemente, y pensé: "Camila habla con sus ojos, no necesita hablar de otra manera." (30)

Relatos como el anterior son la evidencia de la fragmentación del discurso de género impuesto, que sirve de bisagra entre los relatos sociales y aquellas lecturas de la realidad que subvierten las identidades y las normas de género.

El relato de Juliana no niega la convención, más bien lo que persigue es provocar una mirada incómoda pero erotizada que repasa un placer sublime y a la vez terrorífico que desemboca en la enunciación de una identidad de género alternativa. La narración de Juliana descubre sus propias paradojas y las de los encuentros entre su madre y Esteban. Estas situaciones iluminan los pliegues de la protagonista y la enfrentan con el mezquino compromiso que tiene con su familia y con el mundo que la rodea.

Significa entonces que las respuestas no están dadas y las normas establecidas no siempre arrojan una alternativa en términos identitarios. De hecho, la novela de Rosero lo que sí logra es fragmentar el discurso sobre las designaciones fijas de género. Los lectores vislumbran sujetos femeninos eróticos y erotizados que esencialmente se reconocen también en el miedo y el abismo de sus contradicciones. De esta manera, la visión de género unilateral y binaria toma una trayectoria transversal cuando el lector, a través de Juliana, entra en diálogo con los discursos de género y sus prácticas en la actualidad. En efecto, la novela presenta, a través del erotismo, una protagonista con un rango de conciencia frente a sí misma y frente a las interferencias normativas, capaz de disputar un género y una identidad propia aun en medio de la angustia. Vale señalar 
que los dogmas morales resultan insuficientes para definir al sujeto cuando este decide narrarse a través de sus encuentros eróticos. El miedo que siente Juliana en muchos momentos, no frena su experiencia humana ni tampoco su identidad. La protagonista fluye, se activa y se enuncia más allá de las normas que debe cumplir: "tú no serás otra cosa que otro nombre y yo solamente un niño llamándote por otro nombre, hasta que no sepamos cuáles son los nombres nuestros, sólo que tú eres tú y yo soy yo, lo que siempre fuimos, tú y yo mirándonos en silencio" (132). De esta manera, en la narración tiene dominio lo corpóreo, que va trasformando el erotismo en una fuente humana que reformula la existencia.

Cabe agregar que la aplicación de unos valores exclusivos que definen y señalan el alcance de los conceptos de género en términos binarios, propuesta por algunos ciudadanos de bien, no solo deja de cobrar sentido, sino que demuestra el desconocimiento de la ley y de sus garantías. La novela de Rosero, que hoy puede ser leída en Colombia, por el contrario, crea un espacio narrativo idóneo para la exploración de las identidades de género alternativas y así viabiliza la necesidad de repensar el derecho a la igualdad consagrado en la Carta Política. En efecto, Juliana los mira sirve en la actualidad de bisagra entre el discurso motivado por preceptos o valores religiosos y morales que profesan los detractores de las cartillas, quienes rechazaron los acuerdos de paz, y el contenido sustancial de la Constitución de 1991. Viendo los puntos de quiebre del discurso totalizador de género, esta novela de Evelio Rosero se presenta como sugerente territorio para volver sobre la retórica de género y entender hacia dónde apunta el derecho a la igualdad en Colombia. De hecho, es importante saber a quién miramos sin imaginar por qué Juliana los mira.

\section{Bibliografía}

“Acerca de". Colombia Diversa, enero de 2019, colombiadiversa. org/acerca-de-colombia-diversa/

Alto Comisionado para la Paz. Acuerdo Final para la terminación del conflicto y la construcción de una paz estable y duradera. 
Gobierno de Colombia, 24 de noviembre de 2016, www.altocomisionadoparalapaz.gov.co/procesos-y-conversaciones/Documentos\%20compartidos/24-11-2016NuevoAcuerdoFinal.pdf Bataille, Georges. El Erotismo. Tusquets, 2009.

Constitución Política de Colombia. Gaceta Constitucional, no. 116, 20 de diciembre de 2017.

DuPouy, Steven M. Latin American Writers on Gay and Lesbian Themes: A Bio-Critical Sourcebook. Editado por David W. Foster, Greenwood, 1994.

Lemaitre, Julieta. “¿Qué es una ideología de género?”. La silla vacía, 11 agosto 2016, lasillavacia.com/blogs/que-es-una-ideologiade-genero-57494.

Marín Colorado, Andrea. "De la abyección a la revuelta: la nueva novela colombiana de Evelio Rosero, Tomás González y Antonio Ungar." Estudios de Literatura Colombiana, no. 34, enero-junio de 2014, pp. 177-184.

Mazzoldi, Génica, et al. "Debates en torno al enfoque de género en el acuerdo de paz colombiano", 02 de febrero de 2017, www.opendemocracy.net/democraciaabierta/g-nica-mazzoldi-irina-cuesta/debates-transformaciones-y-potencialidades-del-enfoqu.

Rojas Caicedo, Vivian Carolina. La mirada transgresiva en la narrativa de Evelio José Rosero. Tesis de maestría. Universidad del Valle, 2014.

Rosero Evelio. Juliana los mira. Bogotá: Tusquets, 2015.

"Sentencia T-478/15". Corte Constitucional Colombia, 25 de noviembre de 2017, www.corteconstitucional.gov.co/relatoria/2015/t-478-15.htm.

Varderi, Alejandro. Anatomía de una seducción. RIL editores, 2013. 